\title{
Recent Evolution and Status of Online Homework Systems for Teaching Introductory Astronomy
}

Timothy F. Slater ${ }^{1,2 *}$

\begin{abstract}
Internet-delivered, automatically-graded, online homework systems are becoming ever easier for college science teaching faculty to adopt and integrate into existing learning management systems. In this sense, online homework systems have great potential to extend the amount of time on task students allocate to learning astronomy without overburdening already overextended, busy professors. At the same time, the systematic education research surrounding the use of online homework systems is less conclusive, with both benefits and disadvantages being reported in the literature. Moreover, some student advocates lament the financial burden to students and the negative optics about instructors' commitments to teaching. In the end, an ASTR0101 professor's decisions about whether or not to adopt online homework systems are complex and insufficiently supported by compelling education research data and by and large depend heavily on both a professor's teaching philosophy and the academic context in which the students are learning.
\end{abstract}

\section{Keywords}

astronomy teaching - astronomy education research - assessment - online homework systems

${ }^{1}$ University of Wyoming

${ }^{2}$ CAPER Center for Astronomy \& Physics Education Research

${ }^{*}$ Corresponding author: timslaterwyo@gmail.com

\section{Introduction}

In a concerted effort to enhance the introductory astronomy survey course, well-meaning faculty have long endeavored to engineer student behaviors to increase their students' achievement. Absent special circumstances, the traditional student-based formula for student participation in most general education courses for undergraduates is: (i) go to class and take notes; (ii) skim the textbook; and (iii) review notes or provided study guides before the exam; and then (iv) forget everything temporarily learned. Knowing that a student's attendance record is positively correlated with test performance, some faculty require students to attend class, penalizing those students who skip class. Knowing that a student's performance can be improved by providing detailed exam-review guides, some faculty provide students with a formally written outline of the major topics that are likely to be covered by an upcoming exam. Knowing that students who are actively engaged in thinking about astronomical concepts, some faculty try to move students from a passivelistening posture during class to an intellectually engaged orientation by having students discuss concepts with their peers. These engineered student behaviors, among many others, are firmly grounded in the notion widely advocated by long-time astronomy instructors Slater and Adams (2002, 2016) that, "it isn't what the teacher does that matters-it 
is what the students do."

For many faculty, the teaching of general education, introductory astronomy survey courses for non-science majoring undergraduates-hereafter referred to simply as ASTRO101-differs in large parts from the typical approach to teaching the undergraduate introductory physics course sequence. Of many differences between the two courses, including that ASTRO101 is typically filled with nonSTEM majoring undergraduates as compared to introductory physics which almost exclusively enjoys seats filled with enthusiastic STEM majors, the ASTRO101 instructors by and large do not rely on students devoting many hours each week wrestling with outside of class time homework sets characterized by solving numerical problem after numerical problem. Instead, the majority of ASTRO101 faculty by and large do not assign daily or weekly homework to be graded. Although there are certainly exceptions, ASTRO101 faculty do not assign students homework in the same way as physics instructors because, as but one reason, ASTRO101 faculty often teach large-enrollment courses and lack grading assistance in the form of graduate teaching assistants. Moreover, as ASTRO101 courses are largely conceptual in nature rather than calculation-based mathematically intense courses as is typical for physics courses, ASTRO101 narrative-based homework tasks can be more difficult and time consuming to grade than traditional numerical answer-based physics homework. Because of these challenges, along with other pragmatic reasons far too numerous to describe exhaustively here, the tradition of students submitting pages and pages of hand-written homework solutions in ASTRO101 is not widespread.

At the same time, ASTRO101 faculty generally have some tacit sense that students who spend more time dedicated to studying and thinking about astronomy are usually better positioned to be more successful and to learn more than those students who spend less time thinking about astronomy. Under the broad category of "time on task", education researchers agree, and the research literature has consistently confirmed the idea, that students who spend more time immersed in thinking about a subject simply learn more than those who do not (Chickering and Gamson 1987). Given both a natural sense and a robust research-base that students would benefit from spending time outside of class thinking about astronomy, dedicated ASTRO101 faculty have been searching for solutions ranging from developing flipped astronomy classrooms where students learn new information outside of class and come to class to practice applying their new knowledge (viz., Bishop et al. 2013 and references therein) to coming up with innovative hand-grading systems that dramatically reduce the amount of time needed for faculty to hand-grade ASTRO101 homework (Slater 2005).

The appeal for faculty to assign outside of class homework is obvious. For one, assigning students to complete homework outside of class naturally extends the amount of time-time on task — students spend thinking about astronomy. For another, researchers such as Walberg et al. (1985) have clearly demonstrated in two-group comparison studies that graded homework improves student learning more than ungraded homework. Yet, at the same time, Penner et al. (2016) found that, as experienced faculty have tacitly feared, students all too often approach their homework assignments without reading the book and, even more worrisome, that unlimited attempts when using online homework seems to actually reduce student effort. Speaking of online homework system specifically, Gaffney et al. (2010) report that computer graded homework further impersonalizes a course and rarely enhances student satisfaction.

Nonetheless, a broad swath of the ASTRO101 teaching community has long hoped for an emerging technology-based solution that would simultaneously engineer student behaviors to engage in thinking about astronomy while simultaneously not require an extraordinary amount of effort on the part of busy faculty. In other words, as one solution of many possibilities in the solution space, ASTRO101 faculty have long hoped for easy-to-use, automatically graded homework systems to become widely available to support students' enhanced achievement of astronomy. One naturally wonders, given the rapid evolution of emerging Internet technolo- 


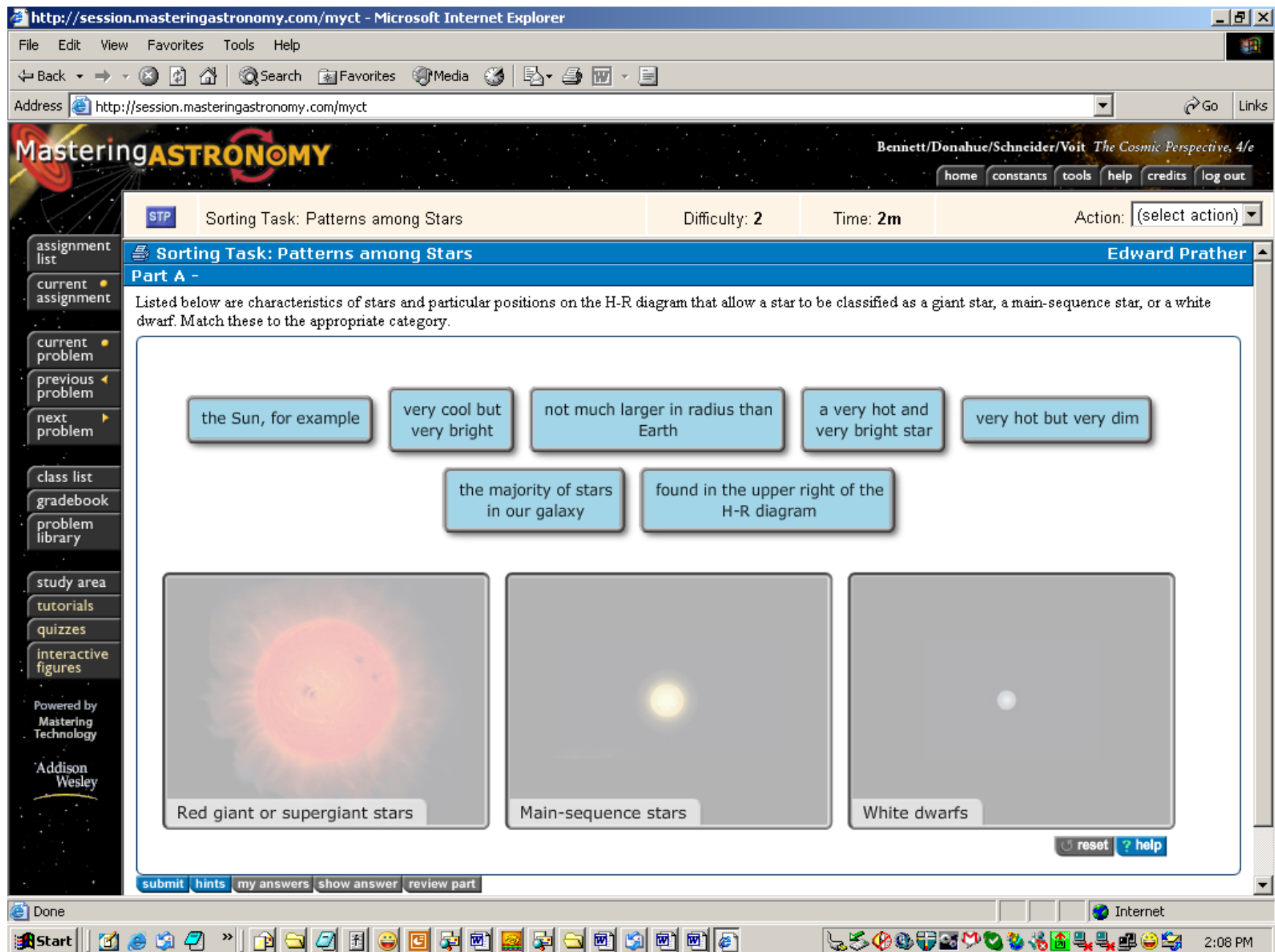

Figure 1. An Illustrative Screenshot Example Of MasteringAstronomy Online Homework System, adapted from Slater (2007). 


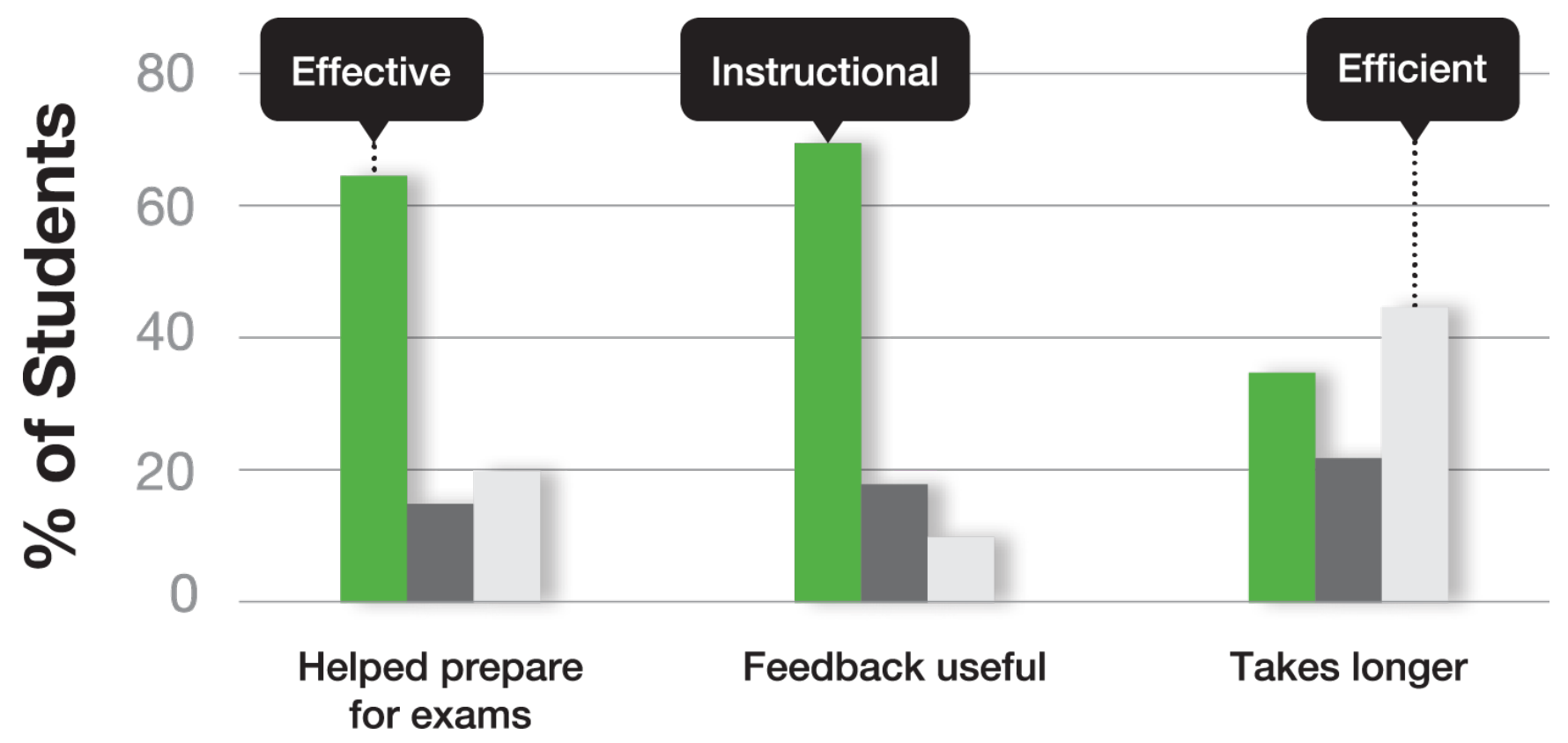

Agree (4 or 5) Neutral (3)

Disagree (1 or 2)

Figure 2. Example of Online Homework Promotional Materials from Macmillan's Sapling Learning System

gies, is the long-awaited time for robust, online homework systems for ASTRO101 finally here?

\section{An Oversimplified History of Online Homework Systems for ASTR0101}

One way to conceptualize the motivation for developing online homework systems appropriate for ASTRO101 is the convergence of two seemingly separate teaching problems in desperate need of solutions. The first motivation, as briefly outlined above, was driven in large part by the needs of overworked and overloaded busy ASTRO101 faculty trying to extend learning and students' engagement beyond traditional in class seat-time to provide more out of class learning experiences in the service of enhancing student achievement. The turn of the Century was characterized by US colleges and universities becoming - for better or worse-more client-oriented which, in turn, resulted in college and university faculty becoming forced to be more accountable to their student-clients. Student suc- cess in learning astronomy, which is appropriately correlated with students giving professors higher end-of-course-evaluation marks (Clayson 2009), requires faculty to provide accountability measures demonstrating their success in teaching students. Homework scores, in addition to exam grades, naturally provides a reasonable accountability measure and, when done well, seems to increase student achievement and end-of-course satisfaction.

At the same time, the number of colleges and universities starting to teach off-campus, distancelearning courses increased dramatically. A complete discussion of why both college administrators and students themselves hungrily desire online courses compared to traditional face-to-face classroom-based courses extends far beyond the realm of this paper, but suffice it to say that faculty presented with the challenge of teaching courses to students off-campus desperately needed secure, online homework systems and course management systems that could go far beyond students handwriting answers to end-of-chapter textbook questions and submitting those assignments electronically, by 
$\times$ Physics Guided Textbook $\times$ WebAssign $\times$

re | https://www.chegg.com/homework-help/textbook-solutions/physics

\section{三 Chegg ${ }^{\circ}$ Study teXtBook solutions EXPERT Q\&A}

home / study / physics / physics solutions manuals

\section{Get Textbook Solutions and 24/7 study help for Physics}

Step-by-step solutions to problems over 22,000 ISBNs

Find textbook solutions

\section{Start typing your question}

\section{Physics Textbooks with Solutions (25)}

\author{
21st Century Astronomy 5th Edition \\ 21st Century Astronomy 5th edition \\ Author: Laura Kay, Stacy Palen, George \\ Blumenthal \\ ISBN: 9780393603330 \\ Edition: 5 th \\ View 857 solutions »
}

\section{1st Century Astronomy 5th Edition}

21 st Century Astronomy 5th edition 21st Century Astronomy 5th Edition

21st Century Astronomy 5th edition

Author: Stacy Palen, Laura Kay, George

Blumenthal

ISBN: 9780393603354

Edition: 5th

View 857 solutions $»$

21st Century Astronomy 5th Edition

21 st Century Astronomy 5th edition

Figure 3. Illustrative Screenshot from Homework Solutions Provider Chegg.com

facsimile FAX machine for example (viz., Keller and Slater 2003; Slater and Jones 2004; Slater and Beaudrie 1998; Slater et al. 2001). Taken together - between the complimentary needs for classroombased ASTRO101 faculty to extend learning beyond the classroom and the needs for distance learning- based ASTRO101 faculty, the time to develop automatically graded, online homework systems at the turn of the Century was ripe.

One of the first widely used online homework systems for ASTRO101 was created by then AddisonWesley Publishing (now Pearson Publishing) to ac- 
company the early editions of The Cosmic Perspective (Bennett et al. 1998) in the late 1990s. In this system, students visited an online webpage using an early-generation web browser, such as Netscape or Mosaic, and answered multiple-choice questions characterized by radio buttons next to possible answers that were then submitted as email to their respective professors by entering the professor's email. Other examples of this sort of firstgeneration online homework system certainly exist.

The next generation of online homework systems were driven by the notion that students would learn more if the received some sort of feedback beyond "right and wrong" from the Internet-based computer system. Leading the development of such a system was a group from MIT led by Dave Pritchard (Morote and Pritchard 2009) in what eventually became the system that is now known widely as MasteringAstronomy (Slater 2007) with significant financial investment by Pearson Publishing, and illustrated in Figure 1. What characterized this next generation online homework system was that when students submitted an incorrect answer to a multiple-choice question, the system would automatically reply with feedback to the student about why a particular incorrect choice was incorrect and provide a hint as to which choice might be correct. Eventually, these systems, known collectively as MasteringX platforms, along with far too many competitors to name, became able to provide rapid feedback to students for text-based and numerical-based responses, both correct and incorrect. Although these systems still fell far short of an imagined intelligent, smart tutor based on artificial intelligence systems, eventually, under the banner of what is generally known as "adaptive testing" some of these advanced generation online homework systems could alter the sequence and difficulty of homework questions delivered to students dependent on students' individual performances.

Today, most major textbook publishers-and a few single-minded companies outside of traditional publishing, such as TheExpertTA.com, among many others-provide students and faculty with a variety of semester- and year-long subscription options for wide array of online homework systems, all with widely varying levels of interactivity and feedback provided. It is not my intention to exhaustively list all of the companies and their available options. Nonetheless, simply because these systems exist is not sufficient reason enough alone for faculty to blindly adopt these systems and require their students to pay subscriptions to them. Although certainly not all, some authors have presented considerable evidence that students learn more when using online homework systems as compared to not (Cheng et al. 2004; Allain and Williams 2006). The publishing companies themselves also point to evidence that online homework matters, as shown in Figure 2. More to the point, Wooten and DillardEggers (2013) offer powerful evidence that online homework systems seem to help lower ability students more than upper ability students if — and that's a hugely important "if" qualifier-students use the computer-based systems to learn concepts rather than simply complete tasks. Taken together, the broader education research jury is still largely undecided regarding the real impact of online homework systems as there is solid research suggesting that many students learn more by laboriously handwriting their lecture-notes and handwriting answers to their homework (Duhigg 2016). In the end, given the current absence of singularly minded educational research landscape, the decision about whether or not to adopt online homework systems still depends largely on a professor's specific learning goals and teaching philosophy.

\section{Is Now the Right Time for You to Adopt Online Homework?}

Much of the future of education is clearly tightly tied to computer delivery. The number of computerbased, online learning modules, seminars, courses and certificate programs is becoming ubiquitous. Even NASA's requirements for all employees and contractors to understand security protocols must be competed annually online. Today, computer-based instruction and assessment falls under the mantra of "we're here; get used to it." As a result, it might seem natural to fall in line with the trend and use computer-based assessment in ASTRO101, despite 
Mark each part of the HR diagram with the correct color.

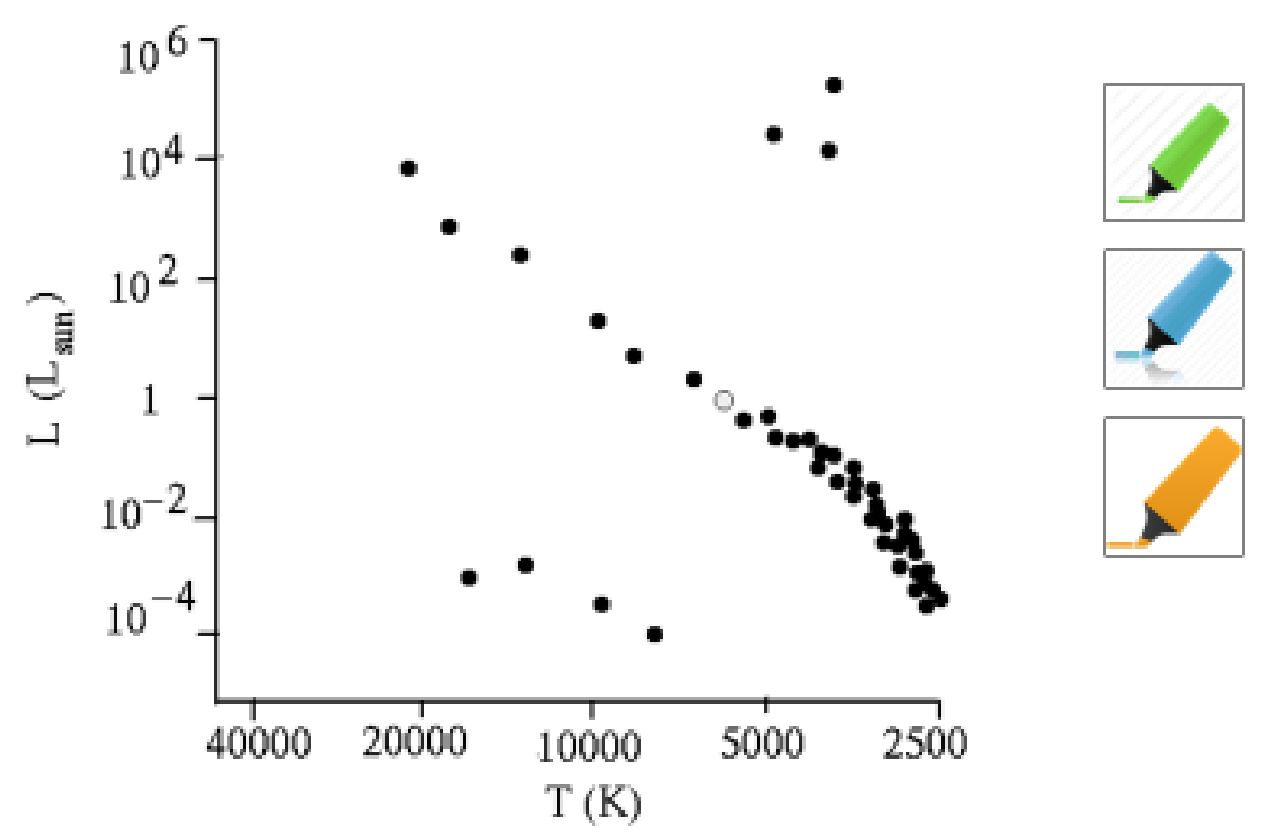

\section{Green: Stars that are fusing hydrogen into helium} Blue: Stars that are fusing helium into heavier elements : Stars that are no longer producing light through

\section{fusion}

Figure 4. A Next-Generation Online Assessment Question Where Students Color-code a HR Diagram, adapted from work by Stephanie J. Slater, Ph.D.

their being insufficiently compelling evidence that online homework systems work as brilliantly as promised by the providers and as sincerely hoped for by compassionate educators.

At the same time that these systems are becoming ever easier and more convenient for busy faculty to use and integrate into their existing learning management systems, the costs to students are increasing. Online homework systems seem to range from about \$30 USD per semester to as much as \$99 USD per semester. Some schools are instituting policies that ban the required use of such systems because of the burgeoning cost burden to students, not to mention the optics of students paying gi- ant tuition bills for faculty who don't even grade student work themselves. Moreover, as with any technological solution, there are also technological undermines. Chegg.com, as illustrated in Figure 3 , are one of many online companies that make money from students selling solution sets to online homework systems. Stated another way, imagine that students pay \$59 USD per semester to subscribe to an online homework system required by a professor and then another \$59 USD per semester to subscribe to the online homework solutions and answers system. With textbooks costing students hundreds of dollars on top of tuition and fees, the burden on students is swelling. 


\section{Conclusion}

Unquestionably, providing students with rapid, formative feedback on their learning improves achievement and attitudes and is worthy of pursuit (Brissenden et al. 2002; Lee et al. 2006). Nevertheless, the bottom line is that the answer to the question of adopting or not adopting online homework systems falls far short of being clear cut. Personally, I am experimenting with online homework systems and anecdotally find that the benefits are outweighing the risks-as of today. I'm trying to prepare myself for the upcoming next-generation of adaptive and responsive online homework systems that could hold tremendous, but as of yet unrealized, promise for individualizing, pacing, and providing video gamelike motivational rewards for a diversity of students to enhance learning. Furthermore, the upcoming generation of online homework systems could be very fun to teach with, such as the assessment task illustrated in Figure 4 where students color code a HR diagram. In the end, I am skeptically enthusiastic about using online homework and feedback technology to help students better understand our place in the universe.

\section{References}

Allain, R. and Williams, T. (2006). The effectiveness of online homework in an introductory science class. Journal of College Science Teaching, 35(6):28.

Bennett, J., Donahue, M., Schneider, N., and Volt, M. (1998). The Cosmic Perspective, 1st Edition. Addison-Wesley.

Bishop, J. L., Verleger, M. A., et al. (2013). The flipped classroom: A survey of the research. In ASEE national conference proceedings, Atlanta, $G A$, volume 30 , pages 1-18.

Brissenden, G., Slater, T., and Matheiu, R. (2002). An assessment primer for introductory astronomy. Astron. Educ. Rev, 1(1):1-24.

Cheng, K. K., Thacker, B. A., Cardenas, R. L., and Crouch, C. (2004). Using an online homework system enhances students' learning of physics concepts in an introductory physics course. American journal of physics, 72(11):1447-1453.

Chickering, A. W. and Gamson, Z. F. (1987). Seven principles for good practice in undergraduate education. AAHE bulletin, 3:7.

Clayson, D. E. (2009). Student evaluations of teaching: Are they related to what students learn? A meta-analysis and review of the literature. Journal of Marketing Education, 31(1):16-30.

Duhigg, C. (2016). Smarter faster better: the transformative power of real productivity. Random House.

Gaffney, M. A., Ryan, D., and Wurst, C. (2010). Do online homework systems improve student performance? In Advances in Accounting Education. Emerald Group Publishing Limited.

Keller, J. M. and Slater, T. F. (2003). The invisible universe online: Design of a distance-learning astronomy course for secondary science teachers. Astronomy Education Review, 2(1).

Lee, K. M., Guidry, M., Schmidt, E. G., Slater, T. F., and Young, T. S. (2006). ClassAction: A Model Rapid-feedback and Dynamic Formative Assessment System. In STEM Assessment Conference, page 141 .

Morote, E.-S. and Pritchard, D. E. (2009). What course elements correlate with improvement on tests in introductory Newtonian mechanics? American Journal of Physics, 77(8):746-753.

Penner, J., Keruze, E., Langsam, S., and Kerueze, J. (2016). Online homework versus pen and pencil homework: Do the benefits outweigh the costs. Special NAAS, pages 1-9.

Slater, T. F. (2005). Save time with a highperformance grading system. The Physics Teacher, 43(6):396-397.

Slater, T. F. (2007). Sorting Tasks and Vocabularyin-Context Activities for Assessing Introductory Astronomy Understanding. 
Slater, T. F. and Adams, J. P. (2002). Learnercentered astronomy teaching: Strategies for ASTRO 101. Addison-Wesley.

Slater, T. F. and Adams, J. P. (2016). Learnercentered astronomy teaching: Strategies for $A S$ TRO 101, 2nd Edition. Pono Publishing.

Slater, T. F. and Beaudrie, B. (1998). Doing Real Science on the Web: Bringing Authentic Investigations to Your Classroom. Learning \& Leading with Technology, 25(4):28-31.

Slater, T. F., Beaudrie, B., Cadtiz, D. M., Governor, D., and Roettger, E. E. (2001). A systemic approach to improving K-12 astronomy education using NASA's internet resources. Journal of Computers in Mathematics and Science Teaching, 20(2):163-178.

Slater, T. F. and Jones, L. V. (2004). Assessment of an internet-delivered interactive approach to introductory astronomy for nonscience majors. Astronomy Education Review, 3(1):17-25.

Walberg, H. J. et al. (1985). Homework's Powerful Effects on Learning. Educational Leadership, 42(7):76-79.

Wooten, T. and Dillard-Eggers, J. (2013). An Investigation of Online Homework: Required or Not Required?. Contemporary Issues in Education Research, 6(2):189-198. 